\title{
DINÂMICA POPULACIONAL DE PLANTAS DANINHAS EM ÁREAS COM SORGO SACARINO E GRANÍFERO COM DIFERENTES ESPAÇAMENTOS E DENSIDADES DE SEMEADURA
}

\author{
TALITA CAMARGOS GOMES ${ }^{1}$ e DÉCIO KARAM ${ }^{2}$ \\ ${ }^{1}$ Universidade Federal de São João del-Rei, Sete Lagoas- MG Brasil, talitacamargos21@gmail.com \\ ${ }^{2}$ Embrapa Milho e Sorgo, Sete Lagoas-MG Brasil, decio.karam@embrapa.br
}

Revista Brasileira de Milho e Sorgo, v.17, n.3, p. 390-399, 2018

\begin{abstract}
RESUMO: O conhecimento de uma comunidade infestante é necessário para se avaliar o nível de dano que esta pode causar na produtividade de qualquer cultura. Assim, o objetivo do estudo foi realizar levantamento fitossociológico exploratório de plantas daninhas em áreas com sorgo sacarino e granífero em função de densidades e espaçamentos de plantas de sorgo como forma de manejo cultural. O estudo foi conduzido em campo, com delineamento experimental de blocos casualizados, em esquema fatorial 2 × 2 × 2 com três repetições, sendo os tratamentos representados por duas cultivares de sorgo, BRS 506 e BR 330, semeadas em duas densidades (100.000, e 200.000 plantas ha $\left.^{-1}\right)$ e dois espaçamentos $(0,25$ e $0,7 \mathrm{~m})$ entre linhas. O levantamento das espécies infestantes foi realizado aos 56 dias após a emergência (DAE) do sorgo, pelo método do quadrado inventário. Observou-se que as diferenças em Índice de Valor de Importância para a mesma espécie daninha estão relacionadas à mudança na densidade e no espaçamento da cultura do sorgo.
\end{abstract}

Palavras-chave: Sorghum bicolor, BRS 506, BR 330, fitossociologia, manejo cultural.

\section{POPULATION DYNAMICS OF WEED IN AREAS WITH SWEET SORGHUM AND GRAIN SORGHUM WITH DIFFERENT SPACINGS AND PLANTING DENSITIES}

\begin{abstract}
Knowing a weed community is important to estimate the level of damage that may cause to the productivity of any crop. Thus, the aim of the present study was to perform a phytosociological survey of weeds in areas with saccharine and grain sorghum considering the interaction between density and spacing of sorghum plants as a form of crop management. The study was conducted at field in a randomized block design with a 2 × 2 × 2 factorial scheme and three replications. Two sorghum cultivars (BRS 506 and BR 330) were seeded at two densities (100,000 and 200,000 plants ha $\left.{ }^{-1}\right)$ and two row spacings $(0.25$ and $0.7 \mathrm{~m})$. The evaluation of the weed species was performed 56 days after emergence (DAE) of sorghum using the inventory square method. The dry mass of the weed species was determined. It was observed that the differences in the importance value index of the same weed species are related to changes in the density and spacing of sorghum.
\end{abstract}

Keywords: Sorghum bicolor, BRS 506, BR 330, phytosociology, crop management. 
A definição de um estudo fitossociológico é basicamente a comparação entre as populações de plantas daninhas, indicando tendências da variação de importância destas populações. Somente após o conhecimento da composição florística da área é feita a tomada de decisão, adotando o melhor método de controle (Oliveira \& Freitas, 2008; Soares et al., 2011). O estabelecimento de uma comunidade de plantas daninhas depende de muitas variáveis, como as condições do tipo de solo, clima, das práticas culturais, do banco de sementes, entre outros fatores (Adegas et al., 2010).

Comumente, estudos fitossociológicos de comunidades infestantes são realizados em determinada fase da cultura, em que a presença das daninhas podem causar uma maior interferência, podendo prejudicar a sua produtividade. A composição florística das comunidades infestantes também varia de acordo com a intensidade dos tratos culturais (Oliveira et al., 2014).

O sorgo (Sorghum bicolor (L) Moench) é uma gramínea cultivada para a produção de grãos em várias regiões do Brasil. Entretanto, o sorgo sacarino vem sendo considerado como alternativa na produção de etanol pelos teores de açúcares contidos em seus colmos (Martins et al., 2017). Em razão da alta tolerância ao estresse hídrico, a cultura do sorgo tem sido utilizada para cultivo na época de safrinha (Almeida Filho et al., 2010). Assim, para um eficiente aproveitamento de radiação solar, dos nutrientes e da água no solo, faz-se necessário conhecer o arranjo espacial ideal das culturas (Albuquerque et al., 2011).

O conhecimento do arranjo espacial mais adequado para cada cultura é necessário, pois constitui prática importante de manejo para a obtenção de produtividades próximas ao potencial produtivo da cultura. Estudos relacionam arranjos espaciais com um adensamento adequado, e consegue-se maiores produtividades. Kappes et al. (2011) testaram dois espaçamentos $(0,45$ e $0,9 \mathrm{~m})$ entre linhas e concluíram que houve melhor produtividade para a espécie de milho (Zea mays) cultivar AG 9010, no espaçamento de $0,45 \mathrm{~m}$. Outros autores verificaram que a redução no espaçamento entre linhas promoveu aumento na produtividade de grãos da cultura do milho (Modolo et al., 2010; Gilo et al., 2011).

A baixa densidade de plantas também permite uma maior penetração de luz no dossel e assim um aumento na taxa fotossintética das folhas do baixeiro, aumentando a produtividade de grãos (Calonego et al., 2011). Mas essa mesma baixa densidade de plantas também permite um maior crescimento e desenvolvimento de plantas daninhas, exigindo então um adensamento adequado tanto para o controle das invasoras quanto para alcançar maior produtividade da cultura. Trabalhos têm sido realizados para se chegar a um melhor adensamento para cada cultura (Silva et al., 2014; Carmo et al., 2018).

O objetivo deste estudo foi avaliar a composição florística e fitossociológica das plantas daninhas em área com sorgo sacarino e granífero, em função da interação entre densidades e espaçamento como forma de manejo cultural.

\section{Material e Métodos}

Os experimentos foram implantados em condições de campo em dois anos agrícolas, na área ex-

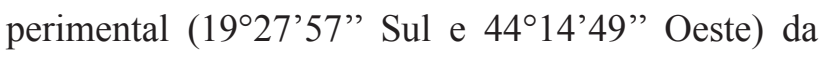
Embrapa Milho e Sorgo, Sete Lagoas-MG , a qual possui clima tropical de altitude e perfil de solo tipo Latossolo Vermelho Distrófico (LDv), escuro e amarelo de textura argilosa. A análise das características físicas e químicas do solo, na camada de 0-20 cm, 
está apresentada na Tabela 1. O preparo do solo foi realizado no sistema convencional, e o manejo da cultura adotado seguiu as recomendações técnicas para a cultura do sorgo sacarino e granífero (Pereira Filho \& Rodrigues, 2015). As adubações na semeadura e cobertura foram realizadas de acordo com recomendações para o sorgo, a partir da análise do solo. De forma semelhante, todos os demais tratos culturais, exceto o controle das plantas daninhas, também foram realizados de acordo com recomendações para a cultura do sorgo (Pereira Filho \& Rodrigues, 2015).

Foram realizados dois experimentos, em que foram utilizadas as cultivares de sorgo BRS 506 (sacarino) e BR 330 (granífero sem tanino). O delineamento experimental utilizado para ambos os experimentos foi de blocos casualizados com três repetições, em esquema fatorial $2 \times 2 \times 2$, com três repetições, sendo os tratamentos representados por cada cultivar de sorgo semeados em duas densidades (100.000, e 200.000 plantas ha $\left.{ }^{-1}\right)$ e dois espaçamentos $(0,25$ e $0,7 \mathrm{~m})$ entre linhas. As unidades experimentais foram constituídas por parcelas com seis linhas de 6 metros, onde foram utilizadas como área úteis as duas linhas centrais das parcelas.

A identificação e a quantificação das espécies de plantas daninhas, assim como a coleta da parte aérea das plantas daninhas, foram realizadas aos 56 dias após a emergência do sorgo (DAE). Foi utilizado o método do quadrado inventário (Braun -Blanquet, 1979), no qual um quadro de $0,25 \mathrm{~m}^{2}$ foi lançado aleatoriamente duas vezes em cada unidade experimental. Após coletadas, as partes aéreas das espécies de plantas daninhas foram levadas à estufa de circulação forçada a $65^{\circ} \mathrm{C}$, para obtenção de massa seca.

Os parâmetros fitossociológicos foram calculados segundo procedimentos descritos por MüellerDombois e Ellenberg (1974), sendo determinados as densidades, abundâncias e frequências, absolutas e relativas, assim como o índice de valor de importância (IVI) de cada espécie. O IVI indica a importância de uma determinada espécie em uma comunidade e é calculado pela soma da densidade relativa, frequência relativa e abundância relativa, expressos em porcentagem. Em complemento, foi calculado o Índice de Similaridade (Sorensen, 1972).



Tabela 1. Composição química do solo na camada de $0-20 \mathrm{~cm}$ de profundidade proveniente do sistema de semeadura convencional onde os experimentos foram implantados.

\begin{tabular}{|c|c|c|c|c|c|c|c|c|c|}
\hline \multicolumn{10}{|c|}{ Sistema de semeadura convencional } \\
\hline \multicolumn{10}{|c|}{ Análise química e física do solo } \\
\hline $\mathrm{pH}$ em $\mathrm{H} 2 \mathrm{O}$ & $\mathrm{P}$ & $\mathrm{K}^{+}$ & $\mathrm{H}^{+} \mathrm{Al}^{3+}$ & $\mathrm{Ca}^{2+}$ & $\mathrm{Mg}^{2+}$ & CTC total & Mo & SB & $\mathrm{V} \%$ \\
\hline \multirow{2}{*}{\multicolumn{3}{|c|}{$\mathbf{m g ~ d m}_{61,11}^{\mathbf{m}}$}} & \multicolumn{7}{|c|}{ cmol cdm ${ }^{-3}$} \\
\hline & & & 5,82 & 9,89 & 1,15 & 16,99 & 4,9 & 11,18 & 65,76 \\
\hline
\end{tabular}




\section{Resultados e Discussão}

\section{Levantamento fitossociológico de plantas daninhas em sorgo sacarino}

Nos dois anos agrícolas, foram identificadas na área total com sorgo sacarino, aos 56 DAE, 17 espécies de plantas daninhas distribuídas em 12 famílias, totalizando 23,41 indivíduos $\mathrm{m}^{-2}$ (Tabela 2). A família mais representativa foi a Poaceae, com um total de 14,83 indivíduos $\mathrm{m}^{-2}$, seguida pela família Rubiaceae com 4 indivíduos $\mathrm{m}^{-2}$. Na densidade de 100.000 plantas ha ${ }^{-2}$, houve 13,16 indivíduos $\mathrm{m}^{-2}$, distribuídos em 9 famílias e 14 espécies diferentes de plantas daninhas. Já na densidade de 200.000 plantas $\mathrm{ha}^{-2}$, foram levantados 9,08 indivíduos $\mathrm{m}^{-2}$ distribuídos em 10 famílias e 15 famílias diferentes de plantas daninhas.
Ao se comparar as duas densidades, houve redução da incidência de plantas daninhas em cerca de $23 \%$ na densidade de 200.000 plantas ha-1 em relação a densidade de 100.000 plantas ha-1 ${ }^{-1}$ As principais espécies encontradas, nas duas densidades e nos dois espaçamentos, aproximadamente $81 \%$ de toda a comunidade de infestantes, foram Bidens sp. (20,8\%), Tridax procumbens (19,56\%), Cenchrus echinatus (19,95\%), Digitaria spp. (23,13\%), Eleusine indica (52\%), Richardia brasiliensis (7,95\%), Spermacoce latifólia (51\%) e Alternanthera tenella (6,6\%) (Tabela 3).

As famílias Poaceae e Asteraceae são as mais comumente encontradas no território brasileiro, em culturas como milho (Vaz de Melo et al., 2007) e o sorgo (Domingos \& Laca-Buendia, 2010) e entre outras (Oliveira \& Freitas, 2008; Gazziero et al., 2004;

Tabela 2. Relação de espécies de plantas daninhas identificadas na aérea experimental com sorgo sacarino BRS 506 nos dois anos agrícolas.

\begin{tabular}{ccc}
\hline & Sorgo BRS 506 (Sacarino) & \\
\hline Família & Espécie & Nome comum \\
\hline Amaranthaceae & Alternanthera tenella & Apaga-fogo \\
Amaranthaceae & Amaranthus viridis & Caruru \\
& Blainvillea latifolia & Erva-palha \\
Asteraceae & Bidens sp. & Picão-preto \\
& Acanthospermum australe & Carrapicho-rasteiro \\
& Tridax procumbens & Erva-de-touro \\
Commelinaceae & Commelina benghalensis & Trapoeraba \\
Compositae & Acanthospermum hispidum & Carrapicho-carneiro \\
Convolvulaceae & Ipomoea sp. & Corda-de-viola \\
Euphorbiaceae & Euphorbia heterophylla & Leiteira \\
Lamiaceae & Leonotis nepetifolia & Cordão-de-frade \\
& Cenchrus echinatus & Timbete \\
Poaceae & Eleusine indica & Capim-pé-de-galinha \\
& Digitaria spp. & Capim-colchão \\
Portualacaceae & Portulaca oleracea & Beldroega \\
Rubiaceae & Richardia brasiliensis & Poaia \\
Rubiaceae & Spermacoce latifolia & Erva-quente
\end{tabular}


Tabela 3. Espécies encontradas e respectivos parâmetros fitossociológicos, amostrados na área total com sorgo sacarino (BRS 506), avaliados aos 56 DAG. DR - (Densidade relativa); FR - (Frequência relativa); AR (Abundância relativa); IVIr - (Índice de Importância relativa).

100.000 plantas ha ${ }^{-1}$

\begin{tabular}{|c|c|c|c|c|c|c|c|c|}
\hline \multirow[b]{2}{*}{ Espécies: } & \multicolumn{4}{|c|}{$0,25 \mathrm{~m}$} & \multicolumn{4}{|c|}{$\mathbf{0 , 7 0} \mathrm{m}$} \\
\hline & AR & FR & DR & IVIr & AR & FR & DR & IVIr \\
\hline Acanthospermum australe & 2,96 & 5,88 & 1,11 & 3,32 & 0,00 & 0,00 & 0,00 & 0,00 \\
\hline Acanthospermum hispidum & 0,00 & 0,00 & 0,00 & 0,00 & 0,00 & 0,00 & 0,00 & 0,00 \\
\hline Alternanthera tenella & 8,87 & 5,88 & 3,33 & 6,03 & 5,88 & 6,25 & 3,03 & 5,05 \\
\hline Amaranthus viridis & 0,00 & 0,00 & 0,00 & 0,00 & 2,94 & 6,25 & 1,52 & 3,57 \\
\hline Bidens spp. & 0,00 & 0,00 & 0,00 & 0,00 & 2,94 & 6,25 & 1,52 & 3,57 \\
\hline Blainvillea latifolia & 0,00 & 0,00 & 0,00 & 0,00 & 0,00 & 0,00 & 0,00 & 0,00 \\
\hline Cenchrus echinatus & 45,32 & 17,65 & 51,11 & 38,03 & 5,88 & 6,25 & 3,03 & 5,05 \\
\hline Commelina benghalensis & 0,00 & 0,00 & 0,00 & 0,00 & 17,65 & 6,25 & 9,09 & 11,00 \\
\hline Digitaria spp. & 4,43 & 11,76 & 3,33 & 6,51 & 35,29 & 18,75 & 54,55 & 36,20 \\
\hline Eleusine indica & 9,85 & 17,65 & 11,11 & 12,87 & 11,76 & 18,75 & 18,18 & 16,23 \\
\hline Euphorbia heterophylla & 0,00 & 0,00 & 0,00 & 0,00 & 2,94 & 6,25 & 1,52 & 3,57 \\
\hline Ipomea spp. & 2,96 & 5,88 & 1,11 & 3,32 & 2,94 & 6,25 & 1,52 & 3,57 \\
\hline Portulaca oleracea & 0,00 & 0,00 & 0,00 & 0,00 & 2,94 & 6,25 & 1,52 & 3,57 \\
\hline Richardia brasiliensis & 14,78 & 17,65 & 16,67 & 16,36 & 2,94 & 6,25 & 1,52 & 3,57 \\
\hline \multirow[t]{3}{*}{ Spermacoce latifolia } & 10,84 & 17,65 & 12,22 & 13,57 & 5,88 & 6,25 & 3,03 & 5,05 \\
\hline & \multicolumn{8}{|c|}{200.000 plantas ha ${ }^{-1}$} \\
\hline & \multicolumn{4}{|c|}{$0,25 \mathrm{~m}$} & \multicolumn{4}{|c|}{$\mathbf{0 , 7 0} \mathrm{m}$} \\
\hline Espécies: & $\mathbf{A R}$ & FR & DR & IVIr & $\mathbf{A R}$ & FR & DR & IVIr \\
\hline Acanthospermum australe & 3,16 & 5,00 & 1,54 & 3,23 & 0,00 & 0,00 & 0,00 & 0,00 \\
\hline Acanthospermum hispidum & 0,00 & 0,00 & 0,00 & 0,00 & 9,00 & 6,25 & 5,17 & 6,81 \\
\hline Alternanthera tenella & 8,42 & 15,00 & 12,31 & 11,91 & 9,00 & 12,50 & 10,34 & 10,61 \\
\hline Blainvillea latifolia & 6,32 & 5,00 & 3,08 & 4,80 & 0,00 & 0,00 & 0,00 & 0,00 \\
\hline Cenchrus echinatus & 13,68 & 15,00 & 20,00 & 16,23 & 4,50 & 12,50 & 5,17 & 7,39 \\
\hline Commelina benghalensis & 9,47 & 5,00 & 4,62 & 6,36 & 9,00 & 6,25 & 5,17 & 6,81 \\
\hline Digitaria spp. & 9,47 & 15,00 & 13,85 & 12,77 & 19,00 & 18,75 & 32,76 & 23,56 \\
\hline Eleusine indica & 10,53 & 15,00 & 15,38 & 13,64 & 22,50 & 12,50 & 25,86 & 20,29 \\
\hline Euphorbia heterophylla & 0,00 & 0,00 & 0,00 & 0,00 & 12,00 & 6,25 & 6,90 & 8,38 \\
\hline Ipomea spp. & 3,16 & 5,00 & 1,54 & 3,23 & 0,00 & 0,00 & 0,00 & 0,00 \\
\hline Leonotis nepetifolia & 0,00 & 0,00 & 0,00 & 0,00 & 3,00 & 6,25 & 1,72 & 3,60 \\
\hline Portulaca oleracea & 0,00 & 0,00 & 0,00 & 0,00 & 6,00 & 6,25 & 3,45 & 5,23 \\
\hline Richardia brasiliensis & 10,53 & 15,00 & 15,38 & 13,64 & 3,00 & 6,25 & 1,72 & 3,66 \\
\hline Spermacoce latifolia & 25,26 & 5,00 & 12,31 & 14,19 & 0,00 & 0,00 & 0,00 & 0,00 \\
\hline Tridax procumbens & 0,00 & 0,00 & 0,00 & 0,00 & 3,00 & 6,25 & 1,72 & 3,66 \\
\hline
\end{tabular}


Adegas et al., 2010; Maciel et al., 2010; Tuffi-Santos et al., 2004). Segundo Tavares et al. (2013), Poaceae é uma das famílias que mais produzem uma grande quantidade de diásporos, facilitando a disseminação de sementes e sua ocupação nos mais diversificados ambientes.

O índice de similaridade obtido entre as duas densidades foi de $66,66 \%$, indicando homogeneidade entre as áreas, o que, segundo Felfili e Venturoli (2000), quando IS\% superior a 50\% pode-se afirmar que existe elevada similaridade entre as áreas. Ao observar o IVI das plantas daninhas no sorgo sacarino BRS 506, na densidade de 100.000 plantas ha-1, a espécie que apresentou maior valor foi $C$. echinatus. Já para a densidade de 200.000 plantas ha ${ }^{-1}$, Digitaria spp. obteve maior IVI, seguida por E. indica, S. latifólia B. pilosa.

\section{Levantamento fitossociológico de plantas daninhas em sorgo granífero}

No levantamento fitossociológico, realizado aos 56 DAG na área total com sorgo granífero BRS 330, nos dois anos agrícolas, foram identificadas 18 espécies distribuídas em 10 famílias, totalizando 36 indivíduos $\mathrm{m}^{-2}$. A família Poaceae foi a mais representativa, com $48 \%$ da população de plantas daninhas, seguida pela Commelinaceae, com $23 \%$ da população de plantas daninhas (Tabela 4). Na densidade de 100.000 plantas $\mathrm{ha}^{-1}$, foram levantados 10,16 in-

Tabela 4. Relação de espécies de plantas daninhas identificadas na aérea experimental com sorgo granífero BRS 330 nos dois anos agrícolas.

\begin{tabular}{ccc}
\hline & Sorgo BRS 330 (Granífero) & \\
\hline Família & Espécie & Nome comum \\
\hline Amaranthaceae & Alternanthera tenella & Apaga-fogo \\
& Bidens spp. & Picão-preto \\
Asteraceae & Acanthospermum australe & Carrapicho-rasteiro \\
Commia kubitzkii & Botão-de-ouro \\
Convolvulaceae & Commelina benghalensis & Trapoeraba \\
Crucíferas & Ipomea spp. & Corda-de-viola \\
Euphorbiaceae & Raphanus sativus & Nabo-forrageiro \\
Lamiaceae & Euphorbia heterophylla & Leiteira \\
Malvaceae & Leonotis nepetifolia & Cordão-de-frade \\
& Sida spp. & Vassoura-de-tatu \\
& Cenchrus echinatus & Timbete \\
Poaceae & Eleusine indica & Capim-pé-de-galinha \\
& Digitaria spp. & Capim-colchão \\
& Brachiaria decumbens & Capim-braquiária \\
& Rhynchelytrum repens & Capim-favorito \\
Rubiaceae & Panicum maximum & Capim-guiné \\
& Richardia brasiliensis & Poaia \\
& Spermacoce latifolia & Erva-quente
\end{tabular}


Tabela 5. Espécies encontradas e respectivos parâmetros fitossociológicos, amostrados na área total avaliada aos 56 DAG. DR - (Densidade relativa); FR - (Frequência relativa); AR - (Abundância relativa); IVIr - (Índice de Importância relativa).

\begin{tabular}{|c|c|c|c|c|c|c|c|c|}
\hline \multirow[b]{3}{*}{ Espécies: } & \multicolumn{8}{|c|}{100.000 plantas ha ${ }^{-1}$} \\
\hline & \multicolumn{4}{|c|}{$0,25 \mathrm{~m}$} & \multicolumn{4}{|c|}{$\mathbf{0 , 7} \mathbf{~ m}$} \\
\hline & $\mathbf{A R}$ & FR & DR & IVIr & $\mathbf{A R}$ & FR & DR & IVIr \\
\hline Alternanthera tenella & 0,00 & 0,00 & 0,00 & 0,00 & 3,53 & 5,56 & 3,53 & 4,45 \\
\hline Bidens spp. & 0,00 & 0,00 & 0,00 & 0,00 & 2,35 & 11,11 & 2,35 & 4,96 \\
\hline Commelina benghalensis & 1,75 & 6,67 & 1,75 & 4,05 & 21,18 & 5,56 & 21,18 & 17,42 \\
\hline Acanthospermum hispidum & 0,00 & 0,00 & 0,00 & 0,00 & 2,35 & 5,56 & 2,35 & 3,58 \\
\hline Ipomoea spp. & 3,51 & 13,33 & 3,51 & 6,86 & 0,00 & 0,00 & 0,00 & 0,00 \\
\hline Raphanus sativus & 0,00 & 0,00 & 0,00 & 0,00 & 3,53 & 5,56 & 3,53 & 4,45 \\
\hline Euphorbia heterophylla & 5,26 & 13,33 & 5,26 & 8,06 & 0,00 & 0,00 & 0,00 & 0,00 \\
\hline Leonotis nepetifolia & 0,00 & 0,00 & 0,00 & 0,00 & 4,71 & 5,56 & 4,71 & 5,31 \\
\hline Sida spp. & 0,00 & 0,00 & 0,00 & 0,00 & 5,88 & 5,56 & 5,88 & 6,18 \\
\hline Cenchrus echinatus & 28,07 & 20,00 & 28,07 & 22,65 & 17,65 & 16,67 & 17,65 & 13,80 \\
\hline Eleusine indica & 40,35 & 13,33 & 40,35 & 32,18 & 1,18 & 5,56 & 1,18 & 2,72 \\
\hline Digitaria spp. & 5,26 & 13,33 & 5,26 & 8,06 & 8,24 & 11,11 & 8,24 & 8,10 \\
\hline Brachiaria decumbens & 0,00 & 0,00 & 0,00 & 0,00 & 1,18 & 5,56 & 1,18 & 2,72 \\
\hline Rhynchelytrum repens & 0,00 & 0,00 & 0,00 & 0,00 & 2,35 & 5,56 & 2,35 & 3,58 \\
\hline Panicum maximum & 0,00 & 0,00 & 0,00 & 0,00 & 7,06 & 5,56 & 7,06 & 7,04 \\
\hline Richardia brasiliensis & 1,75 & 6,67 & 1,75 & 4,05 & 18,82 & 5,56 & 18,82 & 15,69 \\
\hline \multirow[t]{3}{*}{ Spermacoce latifolia } & 14,04 & 13,33 & 14,04 & 14,09 & 0,00 & 0,00 & 0,00 & 0,00 \\
\hline & \multicolumn{8}{|c|}{200.000 plantas $\mathrm{ha}^{-1}$} \\
\hline & \multicolumn{4}{|c|}{$0,25 \mathrm{~m}$} & \multicolumn{4}{|c|}{$\mathbf{0 , 7} \mathrm{m}$} \\
\hline Espécies: & AR & FR & DR & IVIr & AR & FR & DR & IVIr \\
\hline Acanthospermum australe & 4,69 & 7,14 & 2,22 & 4,68 & 0,00 & 0,00 & 0,00 & 0,00 \\
\hline Unxia kubitzkii & 0,00 & 0,00 & 0,00 & 0,00 & 5,19 & 5,26 & 3,08 & 4,51 \\
\hline Commelina benghalensis & 0,00 & 0,00 & 0,00 & 0,00 & 32,47 & 10,53 & 38,46 & 27,15 \\
\hline Ipomoea spp. & 0,00 & 0,00 & 0,00 & 0,00 & 2,60 & 5,26 & 1,54 & 3,13 \\
\hline Raphanus sativus & 0,00 & 0,00 & 0,00 & 0,00 & 5,19 & 5,26 & 3,08 & 4,51 \\
\hline Euphorbia heterophylla & 4,69 & 14,29 & 4,44 & 7,81 & 0,00 & 0,00 & 0,00 & 0,00 \\
\hline Leonotis nepetifolia & 0,00 & 0,00 & 0,00 & 0,00 & 5,19 & 5,26 & 3,08 & 4,51 \\
\hline Sida spp. & 0,00 & 0,00 & 0,00 & 0,00 & 5,19 & 5,26 & 3,08 & 4,51 \\
\hline Cenchrus echinatus & 29,69 & 21,43 & 42,22 & 31,11 & 6,93 & 15,79 & 12,31 & 11,67 \\
\hline Eleusine indica & 16,41 & 14,29 & 15,56 & 15,42 & 2,60 & 5,26 & 1,54 & 3,13 \\
\hline Digitaria spp. & 4,69 & 7,14 & 2,22 & 4,68 & 11,26 & 15,79 & 20,00 & 15,68 \\
\hline Brachiaria decumbens & 9,38 & 7,14 & 4,44 & 6,99 & 5,19 & 5,26 & 3,08 & 4,51 \\
\hline Rhynchelytrum repens & 0,00 & 0,00 & 0,00 & 0,00 & 5,19 & 5,26 & 3,08 & 4,51 \\
\hline Panicum maximum & 0,00 & 0,00 & 0,00 & 0,00 & 5,19 & 5,26 & 3,08 & 4,51 \\
\hline Richardia brasiliensis & 16,41 & 14,29 & 15,56 & 15,42 & 2,60 & 5,26 & 1,54 & 3,13 \\
\hline Spermacoce latifolia & 14,06 & 14,29 & 13,33 & 13,89 & 5,19 & 5,26 & 3,08 & 4,51 \\
\hline
\end{tabular}


divíduos $\mathrm{m}^{-2}$, distribuídos em 7 famílias e 10 espécies diferentes de plantas daninhas. Já na densidade de 200.000 plantas ha $^{-1}$ foram contabilizados 19,33 indivíduos $\mathrm{m}^{-2}$ em 9 famílias e 15 espécies de plantas daninhas encontradas.

Entre as duas densidades, a espécie Cenchrus echinatus compreendeu $28 \%$ da população total de plantas daninhas seguidas por Commelina benghalensi e Spermacoce latifólia, ambas com 12\%. Por meio do IS\%, foi possível inferir sobre a similaridade, que se baseia na presença e ausência das plantas espontâneas entre o cultivo do sorgo nas duas densidades. Praticamente todas as plantas daninhas foram encontradas nas duas densidades, demonstrando uma homogeneidade elevada (80\%). Quando o valor do IS $\%$ é superior a 50\%, pode-se afirmar que existe elevada similaridade entre as áreas em questão (Felfili \& Venturoli, 2000).

Os dados resultantes do levantamento nas áreas das duas densidades revelaram que em maior densidade e espaçamento houve maior diversidade de espécies (Tabela 5). Isto revela que o espaçamento e a densidade são fatores de alto impacto no controle supressivo de plantas daninhas, corroborando com Balbinot Júnior e Fleck (2005), que concluíram que o desenvolvimento de plantas daninhas é afetado com a redução de espaçamento entre linhas das culturas, pois diminui a incidência luminosa no interior do dossel, agindo como controle cultural.

Ao se analisar os parâmetros fitossociológicos, o melhor controle de espécies daninhas foi realizado pelo sorgo sacarino BRS 506 na densidade de 100.000 plantas ha ${ }^{-1}$ no espaçamento de $0,25 \mathrm{~m}$. (Tabela 6). No caso do sorgo granífero, o melhor controle foi realizado pelo espaçamento de 0,25 $\mathrm{m}$ na densidade de 200.000 plantas $\mathrm{ha}^{-1}$. Provavelmente a diferença de controle encontrada entre os dois sorgos se deve à arquitetura que cada cultivar apresenta: o sorgo granífero é de menor estatura, necessitando de um maior adensamento em relação ao sacarino. Deste modo, um plantio mais adensado é capaz de controlar a incidência de plantas daninhas em áreas tanto com sorgo sacarino BRS 506 quanto granífero BRS 330.

Tabela 6. Parâmetros fitossociológicos, amostrados na área total avaliada aos 56 DAG. A - (Abundância); F - (Frequência); D - (Densidade); DR - (Densidade relativa); FR - (Frequência relativa); AR - (Abundância relativa); IVI - (Índice de Valor de Importância).

\begin{tabular}{cccccccccc}
\hline & $\begin{array}{c}\text { Densidade } \\
\text { (plantas ha }^{-1} \text { ) }\end{array}$ & Espaçamento & $\mathbf{A}$ & $\mathbf{F}$ & $\mathbf{D}$ & $\mathbf{A R}$ & $\mathbf{F R}$ & $\mathbf{D R}$ & $\mathbf{I V I}$ \\
\hline Granífero & 100.000 & 0,25 & 40,00 & 3,00 & 0,42 & 20,46 & 9,47 & 12,73 & 42,67 \\
& & 0,70 & 26,83 & 5,00 & 0,59 & 13,73 & 15,79 & 17,70 & 47,22 \\
& 200.000 & 0,25 & 26,50 & 3,00 & 0,40 & 13,55 & 9,47 & 12,11 & 35,14 \\
\multirow{6}{*}{ Sacarino } & & 0,70 & 21,33 & 4,67 & 0,46 & 10,91 & 14,74 & 13,98 & 39,62 \\
& \multirow{2}{*}{00.000} & 0,25 & 15,00 & 2,67 & 0,15 & 7,67 & 8,42 & 4,66 & 20,75 \\
& & 0,70 & 20,50 & 5,00 & 0,47 & 10,49 & 15,79 & 14,29 & 40,56 \\
& \multirow{2}{*}{200.000} & 0,25 & 21,33 & 3,67 & 0,38 & 10,91 & 11,58 & 11,49 & 33,98 \\
& & 0,70 & 24,00 & 4,67 & 0,43 & 12,28 & 14,74 & 13,04 & 40,06 \\
\cline { 3 - 8 } & & Total & 195,50 & 31,67 & 3,31 & 100,00 & 100,00 & 100,0 & 300,0 \\
\hline
\end{tabular}




\section{Conclusões}

A viabilidade do aumento da densidade e a diminuição do espaçamento de semeadura podem ser consideradas como fatores de supressão de plantas espontâneas, podendo ser usadas como ajuda no controle natural dessas espécies.

Há maior supressão de plantas daninhas na densidade de 100.000 plantas ha-1 $^{-1}$ no espaçamento de 0,25 m em plantio de sorgo sacarino (BRS 506).

\section{Agradecimentos}

À Coordenação da Fundação de Amparo à Pesquisa de Minas Gerais (Fapemig) pela concessão da bolsa de estudo.

\section{Referências}

ADEGAS, F. S.; OLIVEIRA, M.F.; VIEIRA, O. V.; PRETE, C. E. C.; GAZZIERO, D. L. P.; VOLL, E. Levantamento fitossociológico de plantas daninhas na cultura do girassol. Planta Daninha, Viçosa, v. 28, n. 4, p. 705-716, 2010. DOI: $10.1590 / \mathrm{S} 0100-83582010000400002$.

ALBUQUeRQUE, C. J. B.; PINHO, R. G. V.; RODEIGUES, J. A. S.; BRANT, R. S.; MENDES, M. C. Espaçamento e densidade de semeadura para cultivares de sorgo granífero no semiárido. Bragantia. Campinas, v. 70, n. 2, p. 278-285, 2011.

DOI: $10.1590 /$ S0006-87052011000200005.

ALMEIDA FILHO, J. E.; TARDIN, F. D.; SOUZA, S. A.; GODINHO, V. P. C.; CARDOSO, M. J. Desempenho agronômico e estabilidade fenotípica de híbridos de sorgo granífero. Revista Brasileira de Milho e Sorgo, Sete Lagoas, v. 9, n. 1, p. 51-64, 2010.

DOI: 10.18512/1980-6477/rbms.v9n1p51-64.

BALBINOT JÚNIOR, A. A.; FLECK, N. G. Benefícios e limitações da redução do espaçamento entre linhas.
Revista Plantio Direto, Passo Fundo, v. 5, p. 37-41, 2005.

BRAUN-BLANQUET, J. Fitossociologia: bases para el estudio de las comunidades vegetales. Madri: H. Blume, 1979. $820 \mathrm{p}$.

CAlONEGO, J. C.; POLETO, L. C.; DOMINGUES, F. N.; TIRITAN, C. S. Produtividade e crescimento de milho em diferentes arranjos de plantas. Revista Agrarian, v. 4, n. 12 , p. $84-90,2011$

CARMO, E. L. do; CARPIM, A. G. R.; SIMON, A.; SILVA, G. G. da; BRAZ, A. P.; BRAGA, G. Adensamento de plantas e épocas de cultivo de soja no cerrado. Colloquium Agrariae, v. 14, n. 2, p. 1-12, 2018.

DOMINGOS, M. K. R.; LACA-BUENDIA, J. P. Levantamento fitossociológico das plantas daninhas na pré-colheita da cultura do sorgo granífero em Uberlândia/ MG. Revista da Fazu, n. 7, p. 68-72, 2010.

FELFILI, J. M.; VENTUROLI, F. Tópicos em análise de vegetação. Brasília, DF: UNB, 2000. 25 p. (Comunicações técnicas florestais, v. 3, n. 2). .

GAZZIERO, L. P. D.; VARGAS, L.; ROMAN, E. S. Manejo e controle de plantas daninhas em soja. In: VARGAS, L.; ROMAN, E. S. (Org.). Manual e controle de plantas daninhas. Bento Gonçalves: Embrapa Uva e Vinho, 2004. p. 595-635.

GILO, E. G.; SILVA JÚNIOR, C. A.; TORRES, F. E.; NASCIMENTO, E. S.; LOURENÇÃO, A. S. Comportamento de híbridos de milho no cerrado SulMato-Grossense, sob diferentes espaçamentos entre linhas. Bioscience Journal, Uberlândia, v. 27, p. 908914,2011

KAPPES, C.; ANDRADE, J. A. da C.; ARF, O.; OLIVEIRA, A. C. de; ARF, M. V.; FERREIRA, J. P. Desempenho de híbridos de milho em diferentes arranjos espaciais de plantas. Bragantia, Campinas, v. 70, n. 2, p. 334-343, 2011.

DOI: $10.1590 / \mathrm{S} 0006-87052011000200012$. 
MACIEL, C. D. G.; POLETINE, J. P.; OLIVEIRA NETO, A. M.; GUERRA, N.; JUSTINIANO, W. Levantamento fitossociológico de plantas daninhas em calçadas do município de Paraguaçu Paulista- SP. Planta Daninha, Viçosa, v. 28, n. 1, p. 53-60, 2010.

DOI: $10.1590 / \mathrm{S} 0100-83582010000100007$.

MARTINS, A. M.; PARRELA, R. A. da C.; LOPES, D. de C.; SCHAFFERT, R. E.; PARRELA, N. N. L. D.; NEVES, W. dos S.; SILVA, A. P. C. M. Período e utilização industrial de cultivares de sorgo sacarino visando a produção de etanol. Revista Brasileira de Milho e Sorgo, Sete Lagoas, v. 16, n. 2 , p. $217-231,2017$

DOI: 10.18512/1980-6477/rbms.v16n2p217-231.

MODOLO, A. J.; CARNIELETTO, R.; KOLLING, E. M.; TROGEllO, E.; SGARBOSSA, M. Desempenho de híbridos de milho na região sudoeste do Paraná sob diferentes espaçamentos entre linhas. Ciência Agronômica, Fortaleza, v. 41, n. 3, p. 435-441, 2010.

DOI: $10.1590 / \mathrm{S} 1806-66902010000300016$.

MÜELLER-DOMBOIS, D.; ELLENBERG, H. A. Aims and methods of vegetation ecology. New York: John Wiley, 1974. $574 \mathrm{p}$.

OLIVEIRA, A. R.; FREITAS, S. P. Levantamento fitossociológico de plantas daninhas em áreas de produção de cana-de-açúcar. Planta Daninha, Viçosa, v. 26, n. 1, p. 33-46, 2008. DOI:10.1590/S0100-83582008000100004.

OLIVEIRA, A. S.; COELHO, F. C.; CREVELARI, J. A.; FERNANDES, I. S.; RUBIM, R. F. Fitossociologia de plantas daninhas em monocultivo de milho e em consórcio com diferentes Fabaceae. Revista Ceres, Viçosa, v. 61, n. 5, p. 643-651, 2014.

DOI: 10.1590/0034-737X201461050007.

PEREIRA FILHO, I. A.; RODRIGUES, J. A. S. Sorgo: o produtor pergunta, a Embrapa responde. Brasília, DF: Embrapa, 2015. 327 p. (Coleção 500 perguntas, 500 respostas).
SILVA, A. F.; SCHONINGER, E. L.; CAIONE, G.; KUFFEL, C.; CARVALHO, M. A. C. Produtividade de híbridos de milho em função do espaçamento e da população de plantas em sistema de plantio convencional. Revista Brasileira de Milho e Sorgo, Sete Lagoas, v. 13, n. 2, 2014.

DOI: 10.18512/1980-6477/rbms.v13n2p162-173.

SOARES, M. B. B.; FINOTO, E. L.; BOLONHEZI, D.; CARREGA, W.; ALBUQUERQUE, J. A. A.; PIROTTA, M. Z. Fitossociologia de plantas daninhas sob diferentes sistemas de manejo de solo em áreas de reforma de cana crua. Agroambiente, v. 5, n. 3, p. 173-181, 2011. DOI: 10.18227/1982-8470ragro.v5i3.594.

SORENSEN, T. A. Method of stablishing groups of equal amplitude in plant society based on similarity of species content. In: ODUM, E. P. Ecologia. 3. ed. México: Interamericana, 1972. p. 341-405.

TAVARES, C. J.; JAKELAITIS, A.; BERNARDO, P. M.; CUNHA, P. C. R. Fitossociologia de plantas daninhas na cultura do feijão. Revista Brasileira de Ciências Agrárias, Recife, v. 8, n. 1, p. 27-32, 2013.

DOI: 10.5039 /agraria.v8i1a1849.

TUFFI-SANTOS, L. D.; SANTOS, I. C.; OLIVEIRA, C. H.; SANTOS, M. V.; FERREIRA, F. A.; QUEIROZ, D. S. Levantamento fitossociológico de pastagens degradadas sob condições de várzea. Planta Daninha, Viçosa, v. 22, n. 1, p. 343-349, 2004.

DOI: $10.1590 / \mathrm{S} 0100-83582004000300003$.

VAZ de MELO, A.; GALVÃO, J. C. C.; FERREIRA, L. R.; MIRANDA, G. V.; TUFFI-SANTOS, L. D.; SANTOS, I. C.; SOUZA, L. V. Dinâmica populacional de plantas daninhas em cultivo de milho verde nos sistemas orgânico e tradicional. Planta Daninha, Viçosa, v. 25, n. 3, p. 521$527,2007$.

DOI: $10.1590 / \mathrm{S} 0100-83582007000300011$. 